\title{
Research on the Strategy of Smart Classroom Construction Based on Teachers' Data Literacy
}

\author{
Yan $\mathrm{Li}^{*}$ and Yuhua Guo \\ Jiaxing Nanhu University, School of Modern Finance, 314001 Jiaxing Zhejiang Province, China
}

\begin{abstract}
The rapid development of quality education and the proposal of the theme of reducing educational burden under the new situation have further promoted the pace of curriculum teaching reform. Exploring the development strategy ofa hybrid teaching model based on knowledge graphs with quality education as the core has important educational practical significance. In the digital age, smart classroom is the inevitable trend of the development of digital technology. Teachers' data literacy reflects the requirements of intelligent classroom for teachers. This paper discusses the connotation of smart classroom and the construction strategy of smart classroom based on Teachers' data literacy, which helps to improve teachers' data literacy, build smart classroom, promote the indepth integration of teachers' data literacy and smart classroom construction, and provide reference for the development of teachers' data literacy and the teaching practice of smart classroom.
\end{abstract}

\section{Introduction}

In the age of education information 2.0 and the modernisation of education 2035, there have been major changes in education and cultural ecology that have brought new opportunities and challenges to classroom teaching. And the traditional classroom is gradually turning to smart classrooms. In the digital age, the smart classroom teaching mode always provides a lot of data on pupil learning behaviour. This requires teachers to use information technology in smart classrooms, to collect pupils' learning data, to use data for evaluation, to improve pupil learning, to analyse and effectively transform these massive data to further promote the creation of a smart classroom, [1] which will improve the practice of smart class building, improve the professional development of teachers, and promote the development of smart learning for pupils. These are the main opportunities and challenges for teachers to implement smart classrooms in the Big Data Age.

That is why teachers in the Big Data Age and in building an smart classroom must have the ability to collect, organise and manage, process and analyse, share and cooperate in innovation and appropriate ethics. Teachers must have data competenc. [2] Teachers' data competence is deeply integrated into the construction of smart classroom. The practical basis for building an smart classroom is then based on teachers' data competence, so the paper discusses the connotation of an smart classroom and the design strategy of an smart

\footnotetext{
*Corresponding author: liyan870223@163.com
} 
classroom on the basis of the data competence of teachers, which contributes to the improvement of the data competence of teachers, establishment of smart classroom and promotion of the deep integration of teachers' competence and smart class building. It is expected that there will be references to the development of teachers' data competence, to the teaching practice of smart classrooms, and to the promotion of the deep integration of teacher data competence and smart class building. [3]

\section{Objective}

From the elements of modern education system, teaching mode is the core element of smart classroom education system. However, the current research status is that the research of smart teaching mode is only carried out at the architectural level and has not been applied in practice, because the hardware required for the application of smart teaching mode is not available and smart classroom teaching mode is a new teaching mode. The hardware facilities do not meet the standards, and the smart teaching mode can only speak on paper; Secondly, the thought of the executor of the smart teaching mode is difficult to change, and the lack of data ability hinders the transformation from the traditional teaching mode to the smart teaching mode, and makes the smart classroom teaching mode based on teachers' data literacy unable to develop in the future. It is necessary to avoid this tendency of only building and not using, and emphasize theory rather than practice; The state and competent authorities must increase investment in the field of smart education, especially equip schools with hardware to implement smart teaching mode; We should actively change teachers' ideas, improve teachers' data ability and make teachers become the main force and form the basis of smart classroom model.

The research objectives are as follows: in terms of design and development as a curriculum project, the smart classroom takes educational interaction as the premise and pays attention to data value mining, so as to promote in-depth learning and knowledge generation. The introduction of intelligent technology will certainly guide the education model from large-scale standardized education to industrialization, and provide students with diversified and personalized teaching. From the perspective of evaluation methods, the evaluation of smart classroom should focus on the evaluation of students in smart classroom, change the evaluation mode and evaluation methods, improve the process and diversity of evaluation, and improve the evaluation level of teacher education.

\section{The connotation of a smart classroom based on teachers' data literacy}

Currently there are different definitions of the smart classroom in science. This article mainly defines the smart classroom from a technical point of view. The so-called "smart classroom" refers to computer science, digitisation, automation and intelligent teaching model, based on the theory of knowledge building in the digital age, and based on dynamic learning data analysis and the application of "Cloud + Terminal", which is inseparably linked to the support of the smart learning environment and highlights the interaction between the learning object and the environment, [4] in particular: The smart classroom emphasizes the wisdom of teachers' classroom teaching results and the intelligent generation of students' learning results. 


\subsection{Smart classroom emphasizes the wisdom of teachers' classroom teaching results and the intelligent generation of students' learning results}

In the smart classroom, teachers should have data literacy so that they can design strategic teaching activities. Teachers' intelligent teaching and students' intelligent learning, evaluation of intelligent teaching and reflection of intelligent teaching run through the whole teaching process, [5] forming a closed and complete intelligent cycle in the whole teaching process, allowing students to deeply participate in the whole teaching process, promoting the development of students' wisdom and guiding students to form intelligent learning achievements.

\subsection{Smart classroom stresses the wisdom and informationization of teaching methods and teaching resources}

In the smart classroom, digital technology is a teaching means and learning resources. As a teaching method, in smart classroom teaching, teachers collect and objectively analyze the relevant data of learning realization, which is helpful for teachers to accurately understand the learning situation and adjust the education plan in time; As a teaching resource in intelligent classroom teaching, digital technology can provide students with a variety of learning resources, make up for the limited use of textbooks as the main learning resources in traditional classroom teaching, be accurate and timely, and encourage the provision of learning resources according to students' individual differences. [6] Students can also choose enough learning resources according to their interests to improve their autonomous learning ability. [7] The smart classroom emphasizes that the teaching relationship is a new type of teacher-student cooperation and student-student cooperation.

\subsection{The smart classroom emphasizes that the teaching relationship is a new type of teacher-student cooperation and student-student cooperation}

In the smart classroom, the communication methods between teachers and students and between students are more diversified. In the smart classroom, students can send information in time through mobile devices, express their opinions in the comment area and send feedback in the mutual evaluation area. These intelligent interaction methods increase the diversity of communication methods between teachers and students and encourage students to actively participate in teaching. Outside the smart classroom, teachers and students can continue to communicate and communicate with others through information technology and cloud terminal platform, so as to extend the teaching process from one class to another, from inside to outside the classroom, so as to truly realize the Information exchange and interactive communication between teachers and students at any time in any place to improve the effect of Education. [8]

Generally speaking, on the one hand, the smart class uses a variety of digital resources to build an intelligent learning environment, integrating in depth the literacy of teachers' data and in-out of class teaching. And it has created a teaching situation that leads to smart teachers' teaching outcomes and smart student learning outcomes. On the other hand, teachers with data literacy combine human wisdom with digital intelligence, project an intelligent learning process through data collection, selection and analysis, guide the intelligent learning of students and improve the richness and efficiency of the results of smart education and the educational media. 


\section{Smart classroom construction strategies based on teachers' data literacy}

\subsection{Policy guidance for the construction of smart classrooms based on teachers' data literacy}

National competent authorities should formulate and issue policies related to the cultivation of teachers' data literacy, build smart classrooms, guide teachers to improve data literacy in the teaching process, strengthen the construction of smart classrooms, and further promote the deep integration of teachers' data literacy and smart classrooms. [9] Many departments of the school should also strengthen the formulation of training policies to ensure the mechanism of combining teaching mode with teachers' data literacy and smart classroom, so as to provide basic conditions and guarantee for the integrated development of the two. In view of the data security problems in smart classroom teaching, the school should also formulate relevant security and confidentiality systems in time to avoid information leakage and ensure the security of teachers' and students' information. [10]

\subsection{Combining Inside and outside the classroom to cultivate the necessary data literacy for teachers in smart classroom teaching}

At present, in smart classroom teaching, most teachers' data literacy cannot reach the standard height, which restricts the construction of intelligent classroom. On the one hand, the competent departments and state school departments must regularly hold lectures and training related to improving teachers' data literacy which will specifically cultivate teachers' purchasing ability, use and analysis ability in combination with the requirements of smart classroom teaching on Teachers' data literacy and Issue corresponding certificates; On the other hand, in the daily process of smart classroom teaching, teachers pay attention to developing the good habit of acquiring, using and analyzing data and cultivating teachers' data awareness, which can accelerate the development of teachers' data literacy and accelerate the pace of smart classroom construction. [11]

\subsection{Strengthen the construction of data platforms and smart classrooms}

In the digital age, schools should pay attention to the creation of smart classrooms and the development of teachers' information skills, but these are inseparable from the development of supporting data platforms. Schools should Strengthen the development of data platform in the design of smart classroom, and build a good data application platform for smart classroom. A good smart classroom data application platform must be able to realize that the data about teachers' smart teaching and students' smart learning can be transmitted quickly and accurately. At the same time, in the process of data platform construction, the school must form a data platform design composed of data administrators and teachers of different disciplines which will be useful for establish an independent data management platform and improve teachers' learning ability and students' learning ability. [12]

\subsection{Accelerate the construction of a community of regional wisdom teaching research and practice}

Nowadays, schools in many cities in China have invested funds to create an intelligent teaching environment with certain configuration, and the development of appropriate intelligent education and teaching rules is read. [13] With the promotion of the project to 
improve the data ability of school teachers, in the process of promoting the whole school in provinces, cities, counties and districts, the construction and establishment of demonstration schools will inevitably transfer to intelligent campus. Training teams and training managers at all levels should seize the opportunity to form a regional intelligent practical education community with intelligent researchers from universities, enterprises and other interested parties jointly studying and exploring intelligent education in practice, so that the empirical research results produced by the best model are more practical. [13]

\section{Conclusions}

In short, teachers' data literacy and smart classroom construction will become the two major themes of today's education. It is of great significance to explore the strategy of indepth integration of teachers' data literacy and smart classroom construction. [14] Smart classroom is the inevitable trend of the development of digital technology. Teachers' data literacy reflects the demand of smart classroom for teachers. With the continuous changes of educational resources, educational ideas and educational methods, smart classroom will become the norm of classroom in the near future. However, due to the limitations of educational policies, teaching resources, teaching methods and evaluation, there is still a certain distance between classroom teaching and teaching evaluation in the current ideal classroom teaching. Within the framework of smart classroom, in terms of teaching resources, teaching methods and teaching methods. Teachers' data literacy is still in the primary development stage, and classroom teaching is still in the primary stage of smart Classroom teaching. [15] With the development of science and technology and the transformation of teachers' teaching ideas, the cultivation of teachers' data literacy and the construction of smart classroom are proceeding in an orderly manner. The deep integration of teachers' data literacy and the smart classroom is just around the corner.

\section{References}

1. Seuk Y P, Seuk W P, Sedigheh M, et al. Effect of Smart Classroom on Student Achievement at Higher Education, Journal of Educational Technology Systems, 48(2):291-304(2019)

2. Malik N, Shanwal V K. A comparative study of traditional and smart classrooms in relation to their creativity and academic achievement, Integrated Journal of Social Sciences, 4(1):15-19(2017)

3. Schifter,C.C., Natarajan, U., Ketelhut, D.J.,et al. Facilitating Teacher Use of Student Data to Inform Classroom Instruction, Contemporary Issues in Technology and Teacher Education, 14(4):419-432(2014)

4. Reeves, T.D., Honig, S.L. A Classroom Data Literacy Intervention for Pre -Service Teachers, Teaching and Teacher Education,50(4):90-101(2015)

5. Thai N T T, De Wever B, Valcke M. The impact of a flipped classroom design on learning performance in higher education: Looking for the best "blend" of lectures and guiding questions with feedback, Computers \& Education, 107(4):113-126( 2017)

6. Vanderlinde R, Aesaert K, Braak J V. Institutionalised ICT use in primary education: A multilevel analysis, Computers \& Education, 72(1):1- 10(2014)

7. Kong H. Study on construction of ai-based english intelligence classroom, Revista de la Facultad de Ingenieria, 32(11):560-564(2017) 
8. Yan-Yan L, Shuang-Gen H, Fu-Yu H. Intelligent Classroom Assistant: the Smart Teaching Tool In Artificial Intelligent, Software Guide,4:20- 29( 2019)

9. Manny-Ikan E , Dagan O, Tikochinski T B , et al. Using the Interactive White Board in Teaching and Learning-An Evaluation of the SMART CLASSROOM Pilot Project, Interdisciplinary Journal of e-Skills and Lifelong Learning, 7:191-198( 2011)

10. Siu Cheung Kong. Developing information literacy and critical thinking skills through domain knowledge learning in digital classrooms: An experience of practicing flipped classroom strategy , Com-puters \& Education,79:160-173(2014)

11. Thomas Wanner, Edward Palmer. Personalising learning: Exploring student and teacher percep-tions about flexible learning and assessment in a flipped university course, Computers \& Education,88:354-360(2015)

12. Martin Forsey. Flipping the sociology classroom: Towards a practice of online pedagogy , Jour-nal of Sociology, 12:471-485(2013)

13. A. Cordero,C. Jordan,E. Sanabria- Codesal.Towards a better learning models through OCWs and MOOCs, International Journal of Artificial Intelligence and Interactive Multimedia,3:25-26(2015)

14. Alpaslan Sahin, Baki Cavlazoglu. Flipping a College Calculus Course: A Case Study, Educa-tional Technology \& Society,18:142-15(2015)

15. LEE, W. H. How to identify emerging research fields using scientometrics an example in the field of information security, Scientometrics, 76 (3):503-525(2008) 